\title{
Resenha
}

Alex da Silva Xavier

Universidade Estadual do Norte Fluminense Darcy Ribeiro (UENF)

\section{Ouvidoria pública brasileira: reflexões, avanços e desafios}

Ronald do Amaral Menezes / Antonio Semeraro Rito Cardoso (Orgs.)

Brasília: Ipea, 2016. 231

ISBN 978-85-7811-272-1

O livro trata do cenário da ouvidoria pública brasileira no contexto atual e levanta os principais debates do campo, especialmente no que diz respeito ao horizonte e desafios dessa agência na mediação dos conflitos entre o poder público e os particulares. A obra é direcionada aos profissionais que atuam em ouvidorias e aos estudiosos do tema. A mesma é organizada por Antonio Semeraro Rito Cardoso, que implementou a Ouvidoria do Instituto de Pesquisa Econômica Aplicada (Ipea) e exerceu três mandatos intercalados de Ouvidor, entre os anos de 2004 e 2014, e Ronald do Amaral Menezes, que exerce a função de Ouvidor do Ipea desde 2014. Ambos os organizadores são funcionários de carreira do instituto.

A apresentação da obra é realizada por Jessé de Souza, Presidente do Ipea na ocasião da publicação da mesma, com prefácio dos organizadores, e dividido em 11 capítulos. Estes estão dispostos de forma que nos cinco primeiros são problematizados conceitos relativos à ouvidoria pública, enquanto nos demais são apresentadas ao leitor experiências de ouvidorias públicas no âmbito federal.

No Capítulo 1, Modelos de ouvidorias públicas no Brasil, Manuel Eduardo Alves Camargo e Gomes, a partir do reconhecimento da diversidade de formatos e modelos de ouvidorias nas três esferas de governo e nos três poderes que formam o Estado brasileiro e da inexistência até então de modelo metodológico que permita agrupá-las, propõe a classificação das mesmas, pautado em dois pressupostos: a) toda ouvidoria possui um conjunto de elementos que devem ser considerados em sua totalidade enquanto característica; b) a existência de uma tipologia ideal para a ouvidoria, conforme lógica Weberiana. Nesse sentido, o recurso

[Resenha recebida em 20 de junho de 2017. Aprovada em 9 de maio de 2018.] 
metodológico utilizado pelo autor refere-se aos critérios estrutural, funcional e unificador, este último apresentado como sinônimo de uma tipologia ideal que permite identificar o modelo a ser classificado. Assim, constrói a possibilidade de agrupar os diversos formatos de ouvidoria em quatro modelos, a saber: ouvidoria interna - esta dividida no subgrupo com autonomia, ou ainda, com participação da sociedade civil; ouvidoria de entidade de controle; ouvidoria interorgânica; e ouvidoria extraorgânica.

O Capítulo 2, Ouvidorias públicas como instrumentos para o fortalecimento da democracia participativa e para a valorização da cidadania, traz a reflexão de Bruno Konder Comparato, que retoma a ideia de participação social no Brasil e no mundo entre as décadas de 1960 e 1980, lendo a mesma como instrumento fundamental para o fortalecimento da democracia. Ao revelar o questionamento da forma tradicional de gerenciamento das políticas públicas pelo Estado, propõe solução a partir da participação popular e introduz as ouvidorias públicas como esse instrumento capaz de efetivar a participação social na implementação de políticas. Nesse sentido, supõe, como fatores que contribuem para justificar o aumento exponencial da ouvidoria nos últimos 50 anos: o aumento da atividade governamental no pós 2 a guerra, a necessidade de garantir direitos humanos, 0 acesso a informação, a discricionariedade dos burocratas de nível de rua e o incentivo à participação. Dessa forma, reconhece o acesso à informação como um direito fundamental e atrela o mesmo à participação social, de modo que associa a existência da ouvidoria à implementação do direito à informação e consequentemente à possibilidade de as pessoas informadas exercerem o controle social, aliando a transparência pública e o combate à corrupção ao aperfeiçoamento da democracia. Não obstante, evidencia uma fragilidade dos demais instrumentos de participação (orçamento participativo, conselhos de políticas e as conferências) na fase de implementação de políticas públicas, e coloca a ouvidoria no centro, como equipamento de monitoramento, avaliador de processo, em se tratando de implementação de políticas públicas.

No Capítulo 3, Ouvidorias públicas e conselhos de políticas: avanços e desafios na democratização da participação social e nas relações entre Estado e sociedade, Fernando Lima Neto e Paulo Renato Flores Durán apresentam os conselhos de políticas e as ouvidorias públicas como instituições políticas potentes no cenário de redemocratização no Brasil. Apontando os mesmos como instrumentos capazes de contribuir para efetivação da democracia, dessa maneira, buscam responder em que medida ambas as instituições avançaram e quais limitações lhes foram impostas, quanto à relação entre o Estado e sociedade. 
Os autores partem do princípio de que a ouvidoria no Brasil (esfera federal, estadual e municipal) está institucionalizada, porém existem poucas informações a respeito, aqui considerando o cenário acadêmico e estatal burocrático. Quanto às ouvidorias, relatam limitações à sua atuação relativas especialmente à inexistência ou baixa autonomia do ouvidor, e isso em consequência do processo de escolha dos mesmos, que geralmente é realizado pela autoridade máxima do órgão ao qual controla. Entendem que a autonomia é elemento-chave para pensar a ouvidoria como possibilidade de instrumento de aperfeiçoamento da democracia. Através de pesquisa realizada pelo Ipea com ouvidorias públicas federais, demonstram que a maioria das ouvidorias possui a autonomia comprometida (técnica e politicamente), seja por escolha interna do ouvidor, seja pela inexistência de poder vinculante.

Em relação aos conselhos, admitem a institucionalização dos mesmos e sua importância para a democracia brasileira, todavia, trazem reflexões quanto à relação entre o trabalho dos conselheiros representantes da sociedade civil e os gestores de governo. Através de revisão bibliográfica, demonstram que a realidade de despreparo dos conselheiros é latente, especialmente daqueles que organicamente representam a sociedade. Avançam na construção da tese de que existe uma fragilidade dos conselhos na contribuição ao processo de democratização, dada a limitação imposta à participação social nas tomadas de decisões e a limitação ao caráter fiscalizatório. Daí defendem a necessidade de reconhecimento dos conselhos como sujeitos políticos de caráter fundamental para o processo democrático e não como benesse do Estado às classes subalternas.

Nessa perspectiva, percebem um avanço das ouvidorias quando adotam posturas proativas e medeiam conflitos entre Estado e sociedade, na direção de um aprofundamento da democracia participativa. Comparativamente, avaliam existir uma distância e uma diferenciação entre o papel e as funções desempenhadas pela ouvidoria e conselhos. A dificuldade referente ao funcionamento da ouvidoria está diretamente ligada à sua base normativa, que limita sua autonomia, entre outras questões, enquanto os conselhos de políticas possuem uma normatização mais efetiva, além de estarem capilarizados nas três esferas de governo, todavia sua limitação na interação prática ainda se apresenta como desafio a ser superado. Enfim, destacam a centralidade desses dois órgãos como instrumentos legítimos de potencial para aperfeiçoamento da democracia, colocando-os como arena de mediação de conflitos políticos e/ou sociais.

No Capítulo 4, As ouvidorias e o uso público da razão: proposta de um modelo ideal-possível à luz dos atos normativos das ouvidorias públicas federais no Brasil, Ronald do Amaral Menezes, Fernando Cardoso Lima Neto e Antonio Semeraro Rito Cardoso tratam de uma discussão pautada em atos normativos, em que retomam 
em análise um conjunto de marcos legais que criam 93 ouvidorias públicas federais, e destes propõem um modelo ideal-possível. Na perspectiva da construção desse modelo, introduzem o tema aprofundando a historicidade da ouvidoria no Brasil e detalham as normatizações dessas ouvidorias no âmbito federal, por intermédio de temas centrais, o que de certa forma complementa essa abordagem já iniciada por Bruno Konder Comparato, no Capítulo 2, e por Fernando Lima Neto e Paulo Renato Flores Durán, no Capítulo 3 do mesmo livro. Assim, a inovação que esse capítulo traz à obra é a construção de um modelo "ideal-possível" que parte da valorização do que cada normatização tem de positivo, considerado o processo de maturidade de políticas públicas, quando se refere aos temas autonomia, mandato, accountability e outros. Um argumento central do capítulo aponta para a necessidade de compreender a construção de um modelo que aciona a lógica de justaposição, em que o ideal é pensado por intermédio de difusão de partes estratégicas de diferentes normatizações.

No Capítulo 5, Paradigmas de ouvidoria pública e proposta de mudança, Rubens Pinto Lyra inicia destacando a singularidade da ouvidoria pública brasileira como órgão que possui caráter unipessoal, todavia, problematizando o modelo de escolha de ouvidor e a magistratura de persuasão do ouvidor, assim como as respectivas consequências desse modelo para o cidadão em relação ao serviço prestado pelo Estado.

Em seguida o autor expõe, através de sete exemplos de ouvidorias brasileiras, todas de atuação em esferas subnacionais, desenhos institucionais paradigmáticos, revelando uma ferramenta de classificação que se atrela de maneira clara à sua defesa por uma constituição de órgão externo ao ente ao qual controla. $\mathrm{O}$ autor defende o pressuposto da preponderância de uma racionalidade dialógica nas ouvidorias públicas, além da necessidade de criação de um sistema nacional de ouvidorias que estabeleça um perfil com padrão mínimo para as mesmas. Segue explorando a contradição na defesa de ouvidorias submissas ao governo, quando as mesmas necessitam de autonomia e independência para dar conta de seu objetivo final: o controle social.

Levanta pontos positivos do Projeto de Lei $n^{\circ} 14 / 2014$, destacando inovações quando comparado com as propostas de legislações anteriores.

Não há dúvidas de que nesse capítulo o leitor encontra o maior crítico brasileiro da ouvidoria pública, tal como essa se encontra estruturada no Brasil. Lyra, com muita propriedade, constrói a tese de ouvidoria pública como instrumento de controle social e aprimoramento da democracia participativa, ademais estabelece críticas diretas não apenas aos governantes que possuem interesse na manutenção do que chama de ouvidorias subordinadas e obedientes, mas também à parte 
considerável de ouvidores e às associações de ouvidores que comungam em boa medida com essa proposta.

Na construção do Capítulo 6, Os dez anos da ouvidoria do Ipea, Ronald do Amaral Menezes e Antonio Semeraro Rito Cardoso expõem, por intermédio dos estágios do desenvolvimento organizacional de Lippitt (1969), o ciclo de vida da ouvidoria no Ipea. Isso permite que, na mesma medida em que apresentam o histórico, também refletem os desafios e potencialidades da experiência, oferecendo ao leitor uma contribuição prática para pensar o desenho institucional e as funcionalidades de uma instituição de controle e participação social. Nesse capítulo, a despeito de se tratar de um relato de experiência, é possível observar uma construção de ouvidoria que a todo tempo refere-se a uma bagagem teórica, traduzindo um processo de construção reflexivo do próprio órgão. Por fim, são apresentados alguns números que trazem ao leitor parâmetros quantitativos do trabalho realizado.

No Capítulo 7, A importância da ouvidoria para o serviço público: o caso da Previdência Social, Francisco Assis Santos Mano Barreto e Garibaldi Alves Filho em grande medida constroem um histórico da Ouvidoria-Geral da Previdência Social (OGPS), desdobrando entre os anos de 1998 e 2014 algumas ações de destaque, desde sua criação, passando por construção de sistema eletrônico, carta de serviço, até criação de grupo para resolução de manifestações pendentes. Em seguida descrevem a estrutura e funcionamento do serviço, através da apresentação de números de manifestações, e outros dados.

Contudo, apesar de afirmarem na parte final do capítulo a existência de algumas lições aprendidas e desafios - tais como o fato de não apenas mediar conflitos, mas de acolher novas necessidades e tendências da Previdência Social, o que justifica a expectativa atribuída ao título do capítulo -, as reflexões apontam para uma agenda futura de estudos e acesso a detalhes de tais lições e desafios e para a forma que a OGPS e outras ouvidorias os têm tratado.

O Capítulo 8, A Ouvidoria do Serviço Florestal Brasileiro, de Fernanda da Silveira Campos, apresenta o cenário de criação da ouvidoria no Serviço Florestal Brasileiro (SBF) e a partir disso constrói uma avaliação do serviço pautada em três estágios de implementação, cuja referência evidencia os três momentos diferentes quanto aos mandatos do ouvidor. Cabe destacar, que o primeiro momento é iniciado em 2010, ano que a ouvidoria inicia seu funcionamento, ainda que sua formulação tenha ocorrido desde 2006, através da mesma lei que criou o SFB. O segundo momento entre abril e dezembro de 2011, é apresentado como lapso do serviço de ouvidoria, considerando a ausência de um ouvidor nomeado. Já no terceiro estágio, a ouvidoria retoma suas atividades de forma efetiva. A autora segue apresentando a ouvidoria demonstrando em números sua trajetória, além de retomar a questão da 
avaliação do serviço prestado por intermédio da pesquisa de avaliação realizada. Já no caminho para finalização do capítulo, são apresentados 13 destaques, referentes à participação da ouvidoria. Dentre esses destaques, a implementação da Lei de Acesso à Informação ocupou o maior espaço de reflexão, considerado o papel ativo e a responsabilidade de implementação.

A exposição realizada nesse capítulo, na mesma medida em que demonstra uma experiência importante no que diz respeito à conquista de espaço da ouvidoria e aos desafios para sua implementação e continuidade, também deixa claro a fragilidade da manutenção do serviço de ouvidoria, quando o seu desenho institucional não provê um processo claro de escolha do ouvidor e uma garantia de mandato. Isso corrobora os riscos ressaltados por Lyra (2004), em relação ao modelo predominante de ouvidoria no Brasil.

No Capítulo 9, A efetividade da Ouvidoria-Geral da União, José Eduardo Elias Romão aborda elementos que buscam responder em que medida a OuvidoriaGeral da União (OGU), no quadriênio 2011-2014, contribuiu para a promoção de processos de participação social que tenham provido melhorias no funcionamento do governo, na estruturação de políticas públicas e consequentemente na qualidade de vida e acesso das pessoas às ações e serviços públicos. Para responder a essa ambiciosa questão, o autor retoma cada passo do caminho histórico e metodológico trilhado para construção do Sistema de Ouvidorias do Poder Executivo federal. No texto é possível acompanhar os embates e interesses em disputa em torno da formulação da política pública de ouvidoria, e, por fim, concluir como se deram os avanços e retrocessos considerada tal trajetória política. Conforme Arretche (2005) e Menicucci (2007), fica clara a não linearidade da implementação da política e os conflitos de interesse (técnicos e políticos) em disputa, expondo-se o dinamismo do processo.

No Capítulo 10, Ouvidorias públicas no contexto do novo serviço público: o caso da Ouvidoria da Receita Federal do Brasil - 1a Região Fiscal, Marcia Christina dos Santos Rabelo e Joana Luiza Oliveira Alencar partem do referencial do novo serviço público para justificar a existência da ouvidoria na perspectiva de instrumento de diálogo e troca entre o cidadão e o Estado. Dessa forma, se debruçam sobre o conceito e seis princípios do novo serviço público para, a partir de então, abordar a ouvidoria pública. Por fim, trazem a experiência da ouvidoria virtual da Receita Federal do Brasil, justificando com a experiência vivida a possibilidade de boa interlocução entre indivíduos e Estado por intermédio do ciberespaço, mesmo se tratando de mediações de ouvidoria.

O Capítulo 11, Projeto Coleta OGU 2014: um retrato das ouvidorias federais brasileiras, de Ronald do Amaral Menezes, apresenta o projeto cujo objetivo foi 
conhecer a atuação e funcionamento das ouvidorias públicas, especialmente as que atuam em âmbito federal, para construção de elementos capazes de desenhar o Sistema Federal de Ouvidorias Públicas e formular políticas públicas para o mesmo. O projeto reuniu dados de 163 ouvidorias federais e possibilita uma radiografia inicial das ouvidorias no cenário federal, trazendo respostas importantes no sentido de apontar como tem avançado a implementação das ouvidorias naquela esfera. Assim, aborda o comportamento quanto à normatização, estrutura organizacional, perfil sociodemográfico dos ouvidores, experiência dos ouvidores na função, estrutura de pessoal e processo de escolha do ouvidor. É possível ainda verificar como se organiza a gestão dos processos de trabalho das ouvidorias, se trabalham com divulgação de relatórios e pesquisa de satisfação, planos de metas e outros. Bem como é possível verificar informações quanto à atuação das ouvidorias, revelando os canais de entrada utilizados, tipos e número de manifestações e resolução das mesmas, além de dificuldades para promover a participação social.

A escolha das experiências colocadas no debate propicia à obra uma especificidade em relação à abordagem da ouvidoria genuinamente pública, a saber, essas experiências são abordadas por autores que vivem os desafios cotidianos dos respectivos serviços. Na primeira parte do livro - entre os capítulos 1 e 5 -, em que os organizadores se propõem realizar discussões conceituais sobre ouvidoria pública, são trazidos um conjunto de autores com grande formação e experiência acadêmica, além da experiência prática no campo da ouvidoria. Merece destaque nesse sentido o Prof. Dr. Manoel Eduardo Alves Camargo e Gomes, autor do Capítulo 1, que em 1986 assumiu a função de Ouvidor do Município de Curitiba, primeira ouvidoria pública do país. Além de primeiro ouvidor, Manoel Eduardo seguiu a vida acadêmica demonstrando interesse pelo tema e construiu no doutorado a tese intitulada O regime jurídico das ouvidorias públicas brasileiras: causalidade de sentido e adequação estruturo-funcional, defendida em 2001. Destaca-se também o Capítulo 5, do Prof. Dr. Rubens Pinto Lyra, que reúne uma quantidade muito expressiva de publicações específicas a respeito de ouvidoria pública, e também ocupou o cargo de Ouvidor Geral da Universidade Federal da Paraíba entre os anos de 1999 e 2003.

Já na segunda parte - entre os capítulos 6 e 11 -, dedicada ao cotidiano dos serviços de ouvidoria, a exposição é realizada, em sua maior parte, pelos próprios ouvidores das respectivas instituições. Aqui é importante apontar a participação do Dr. José Eduardo Elias Romão, que foi Ouvidor-Geral da União entre 2011 e 2015, período de intenso debate para formulação de um sistema nacional de ouvidorias.

Na obra, o autor mais citado nos capítulos é Rubens Pinto Lyra. Ainda que se considere às vezes que a citação consiste em uma crítica, na maioria das vezes a 
referência faz menção à concordância com os seus estudos. Entre os 11 capítulos, apenas 2 - o capítulo 7 e o 10 - não fazem menção em momento algum a Lyra, o que demonstra em grande medida a força das críticas por ele defendidas, em relação à ouvidoria pública brasileira. Podemos observar ainda várias referências aos trabalhos de Manuel Eduardo Alves Camargo e Gomes e, de forma um pouco mais tímida, todavia considerável, as citações a Leonardo Avritzer. Essas estão presentes especialmente na primeira parte do livro, mais teórica, o que revela a íntima relação que o tema ouvidoria possui com a teoria democrática e da participação.

No que diz respeito à proposta de abordar a ouvidoria pública brasileira, claramente o livro privilegia a experiência da ouvidoria no âmbito do Executivo federal, dado que, mesmo na primeira parte, em que os autores buscam um recorte mais teórico, é possível verificar nos capítulos 3 e 4 um enfoque nas experiências do Executivo federal. No mais, a segunda parte da obra foca nas vivências de instituições circunscritas também à esfera do Executivo central, e não avança no sentido de trazer ao leitor experiências vivenciadas no âmbito subnacional dos estados e municípios, ou ainda dos demais Poderes: Legislativo e Judiciário. A citação de algumas experiências municipais fica restrita a exemplos que ajudam a compreensão da classificação de modelos abordados apenas no primeiro capítulo. Cabe aqui deixar claro que tal constatação não diminui em nada a riqueza do conteúdo do livro e as contribuições que o mesmo traz aos seus leitores, mas tem por objetivo apontar que, ao abordar a ouvidoria pública brasileira, tal qual se propõe no título, o livro traz o desafio de colocar na agenda de pesquisas a questão também nas esferas estadual e municipal, haja vista a relevância do pacto federativo brasileiro para os contornos e desenhos das políticas públicas nacionais ou locais.

A obra colabora para preencher uma lacuna quanto à existência de uma classificação que permita agrupar a variedade de desenhos institucionais desses órgãos. Definitivamente trata-se de um livro de importância ímpar na abordagem da ouvidoria pública no Brasil. A despeito de tratar especificamente da ouvidoria pública no Executivo federal, com exceção ao capítulo do Rubens Lyra, que aborda ouvidorias em outros poderes ou esferas de governo, a obra apresenta de forma rica a ouvidoria como um importante instrumento de controle/participação social. Coloca no centro a discussão a respeito do desenho institucional, escolha e mandato do ouvidor, autonomia e poder vinculante do instituto, além de levantar um histórico da política pública de ouvidoria no Brasil. 


\section{Referências bibliográficas}

Arretche, Marta. A política da Política de Saúde no Brasil. In: LiMA, Nísia Trindade; Gerschman, Silvia; Edler, Flavio Coelho; SuAREZ, Julio Manuel. (Orgs.). Saúde e democracia: história e perspectivas do SUS. Rio de Janeiro: Fiocruz, 2005.

LIPPITT, G. Organization renewal. Englewood Cliffs: Prentice Hall, 1969.

LYRA, R. P. Autônomas $x$ obedientes: a ouvidoria pública em debate. João Pessoa: Editora UFP, 2004. p. 172.

MccubBINS, M. D.; SCHWARTZ, T. Congressional oversight overlooked: police patrols versus fire alarms. American Journal of Political Science, v. 28, n. 1, p. 165-179, fev. 1984.

MENICUCCI, Telma Maria Gonçalves. Implementação da reforma sanitária: a formação de uma política. In: Hochman, Gilberto; ARRETCHE, Marta; MARQUES, Eduardo. (Orgs.). Políticas públicas de saúde no Brasil. Rio de Janeiro: Editora Fiocruz, 2007.

Peruzzotti, E.; Smulovitz, C. Accountability social: la otra cara del control. In. Peruzzotti, E.; SMulovitz, C. et al. Controlando la política. Ciudadanos y medios en las democracias latinoamericanas. Buenos Aires: Grupo Editorial Temas, 2002.

\section{Alex da Silva Xavier}

Mestre em Saúde Coletiva pela Universidade Federal Fluminense (UFF) e doutorando em Sociologia Política pela Universidade Estadual do Norte Fluminense (UENF). Contato: xavier_fisio@yahoo.com.br 
RSP 